\title{
Relative safety of steroid sparing agents in frequently relapsing, steroid dependent and steroid resistant nephrotic syndrome in pediatric patients
}

\author{
Sabnam Ara Begum ${ }^{1}$, Santanu Kumar Tripathi ${ }^{2}$, Mousumi Nandy ${ }^{3}$, Sanat Kumar Ghosh ${ }^{4}$, \\ Shatavisa Mukherjee ${ }^{2 *}$, Debajyoti Saha ${ }^{2}$
}

\begin{abstract}
${ }^{1}$ Department of Pharmacology, R. G. Kar Medical College, Kolkata, West Bengal, India
${ }^{2}$ Department of Clinical and Experimental Pharmacology, School of Tropical Medicine, Kolkata, West Bengal, India

${ }^{3}$ Department of Paediatric Medicine, Medical College, Kolkata, West Bengal, India

${ }^{4}$ Department of Paediatric Medicine, Dr. B. C. Roy Post Graduate Institute of Paediatric Sciences, Narkeldanga,

Kolkata, West Bengal, India
\end{abstract}

Received: 07 June 2020

Accepted: 30 June 2020

\section{*Correspondence:}

Shatavisa Mukherjee,

E-mail: shatavisa100@gmail.com

Copyright: (c) the author(s), publisher and licensee Medip Academy. This is an open-access article distributed under the terms of the Creative Commons Attribution Non-Commercial License, which permits unrestricted non-commercial use, distribution, and reproduction in any medium, provided the original work is properly cited.

\section{ABSTRACT}

Background: In patients with frequently relapsing nephrotic syndrome (FRNS), steroid-dependent nephrotic syndrome (SDNS) and steroid resistant nephrotic syndrome (SRNS) steroids are either used for prolonged period of time or ineffective. To reduce the degree of steroid dependency and avoid steroid toxicity, several immunosuppressive steroid sparing agents (SPAs) have been proposed to treat these children. The present study tried to study the relative safety of most commonly steroid sparing agent in such children.

Methods: A multi-centred, prospective observational study was conducted in paediatric nephrology OPD of two tertiary care hospitals in Kolkata over a period of 24 months. All consecutive children with diagnosed FRNS, SDNS and SRNS who were started on steroid sparing agents were enrolled and followed up for at least 6 months. Records of clinical examination, laboratory tests were collected and measured at the baseline and regular intervals. Safety parameters were noted and statistically analysed.

Results: A total 110 patients were screened, examined and enrolled. Levamisole, cyclophosphamide and MMF were commonly used SPAs. Of the two tertiary care hospitals, all the patients of FRNS and SDNS were started with levamisole and SRNS with cyclophosphamide in one set-up, while in the other hospital some SDNS patients were started with cyclophosphamide and SRNS with MMF but without clinically significant outcomes. In comparison with few minor adverse events in MMF group, some serious adverse events were documented in the both cyclophosphamide and levamisole groups.

Conclusions: Levamisole being a very efficacious, safe and easily affordable drug, should be used as an initial first line SPA in treating FRNS and SDNS children. The side effect profiles of levamisole and MMF are much more patient friendly.

Keywords: Frequently relapsing nephrotic syndrome, Safety, Steroid-dependent nephrotic syndrome, Steroid resistant nephrotic syndrome, Steroid sparing agents

\section{INTRODUCTION}

Nephrotic syndrome (NS) is the most frequent glomerular disease in childhood, with reported incidence varying from two to seven cases per 100,000 children. ${ }^{1}$ Before the introduction of antibiotics, corticosteroids, and other immunosuppressive therapies, nephrotic syndrome was associated with mortality as high as $67 \%$, usually 
following infections. The first significant improvement in mortality was seen in 1939 after the introduction of sulfonamides and then penicillin. It is estimated that about $80 \%$ of children with idiopathic nephrotic syndrome will respond to corticosteroid treatment with complete resolution of proteinuria and edema. Among this steroid responsive group, the clinical course is variable, with up to $60 \%$ having frequent relapses or becoming dependent on steroid therapy to maintain them in remission.

Diagnosis of nephrotic syndrome requires the presence of edema, massive proteinuria $\left(>40 \mathrm{mg} / \mathrm{m}^{2} /\right.$ hours or a urine protein/creatinine ratio $>2.0 \mathrm{mg} / \mathrm{mg}$ ), and hypoalbuminemia $(<2.5 \mathrm{~g} / \mathrm{dl}))^{2,3}$ Patients who enter remission in response to corticosteroid treatment alone are referred to as having steroid-sensitive nephrotic syndrome (SSNS), while patients who fail to enter remission after 8 weeks of corticosteroid treatment are referred to as having steroid-resistant nephrotic syndrome or (SRNS). ${ }^{2,3}$ Some patients respond to initial corticosteroid treatment by entering complete remission but develop a relapse either while still receiving steroids or within 2 weeks of discontinuation of treatment following a steroid taper. Such patients typically require continued low-dose treatment with steroids to prevent development of relapse, and are therefore referred to as having steroid-dependent nephrotic syndrome. ${ }^{4}$

Some patients enter complete remission in response to steroids and remain in remission for several weeks following discontinuation of treatment but develop frequent relapses. If relapses occur 2 or more time in any 6 months period or 4 or more times in any 12-month period, these patients are referred to as having frequent relapsing nephrotic syndrome (FRNS). ${ }^{4}$ Both SDNS and FRNS patients are at increased risk of developing complications of nephritic syndrome and complications from frequent use of steroids and other immunosuppressive agents.

Most patients are steroid responsive, achieving complete remission, but about $70 \%$ will relapse. ${ }^{5}$ Of those, $60 \%$ relapse frequently or become steroid-dependent. ${ }^{5}$ In patients with frequently relapsing nephrotic syndrome (FRNS), steroid-dependent nephrotic syndrome (SDNS) and steroid resistant nephrotic syndrome (SRNS) steroids are usually ineffective. In some case where they are used in high doses and prolonged period of time side effects of steroids can occur, including growth failure, obesity, hypertension, osteoporosis, hirsutism etc. To reduce the degree of steroid dependency and avoid steroid toxicity, several steroid sparing immunosuppressive agents have been proposed to treat these children. ${ }^{6}$ The treatment of FRNS, SDNS and SRNS continues to be a difficult challenge. Several studies indicate that steroid sparing agents (SPA) like levamisole, cyclophosphamide (Cyp), mycophenolate mofetil (MMF), cyclosporine, azathioprine, chlorambucil, tacrolimus, or rituximab can be used for the treatment of frequently relapsing, steroid- dependent or steroid-resistant NS. There exists a lack of harmony in recommendations and practices may impact the outcomes of patients. The present study tried to assess the safety outcomes in cases of FRNS, SDNS and SRNS - especially treatment with the steroid sparing agents.

\section{METHODS}

A multi-centre, observational prospective study was carried out in the out-patients department clinics of pediatric nephrology department in two tertiary care teaching hospital in Eastern India over a period of 24 months. Enrolment of patients commenced after having obtained the approval from the institutional ethics committees of the respective institutes. Children of either sexes, aged 2-12 years, attending the out-patients department (OPD) of the two hospitals, diagnosed as FRNS, SDNS and SRNS, and put on steroid sparing agents for the first time and consenting to participate were included. Cases of acute illness, NS with secondary aetiology, congenital NS and those to be optimally compliant and not cooperative were excluded. Clinical presentation, medication history along with basic demographics was noted. Details of adverse drug reactions were captured in a pre-structured data collection form and were analyzed for causality and severity using WHO-UMC causality assessment scale and HartwigSeigel severity assessment scale respectively. ${ }^{7,8}$

\section{RESULTS}

A total 110 subjects were screened and recruited at two study sites of pediatric nephrology OPD clinics of two tertiary care hospitals in Kolkata over a period of one year. Among them 6 subjects refused in giving consent in this study; therefore 104 subjects were enrolled. All enrolled subjects were followed up monthly for 6 months. Out of the total of 104 patients enrolled in the study 44 were diagnosed as SDNS, while 56 were diagnosed as FRNS, and 4 patients were diagnosed as SRNS. Out of a total of 104 patients enrolled in the study, levamisole, Cyp and MMF were commonly used SPAs. Among them levamisole was the most commonly used SPA (97 out of 104 subjects). All of the SDNS subjects were put on levamisole; while 53 among total 56 FRNS subjects were started with levamisole and 3 with Cyp. In case of 4 SRNS, 2 were started with Cyp and 2 with MMF. At presentation, the mean age of the patients was $6.68 \pm 2.29$ years with male: female ratio being 2.6:1 (Table 1).

\section{Relative safety of the commonly used steroid sparing therapy}

There were five subjects were started with Cyp at the beginning of the study but due to treatment failure with levamisole eight subjects were changed to Cyp therapy and one subject to MMF due to Cyp therapy failure. Authors analyzed side effects of all the subjects receiving Cyp $(n=13)$ and MMF $(n=3)$. Adverse effects with all the SPAs are shown in Table 2. 
Side effects were noted with MMF (n=6), but were mostly minor. Only one subject required temporary reduction in the dose of MMF due to elevated liver enzymes but not required permanent discontinuation of MMF. Authors have found 2 patients of FRNS treated with Cyp developed hyper-pigmentation at the dorsum of the hand and nail after 4 weeks of starting Cyp therapy and disappeared 4 weeks of stoppage of treatment. Since mood change, cushingoid habitus, hirsutism can also be attributed to the accompanying steroids; authors assume that there were no direct adverse events caused by levamisole, Cyp or MMF itself.

Table 1: Basic demographics of study subjects.

\begin{tabular}{|llll|}
\hline Female & FRNS $(\mathbf{n}=\mathbf{5 3})$ & SDNS $(\mathbf{n}=\mathbf{4 4})$ & Total \\
\hline Male & 13 & 14 & 27 \\
\hline Age at onset of FRNS and SDNS $($ Mean \pm SD) & 40 & 30 & 70 \\
\hline Age at onset of nephrotic syndrome (Mean \pm SD) & $6.58 \pm 2.12$ & $6.80 \pm 2.49$ & $6.68 \pm 2.29$ \\
\hline
\end{tabular}

Table 2: Spectrum of adverse effects with SPAs.

\begin{tabular}{|llll|}
\hline & Levamisole & Cyclophosphamide & MMF \\
\hline Gastrointestinal system & & 2 & 1 \\
\hline Nausea & 56 & 0 & 1 \\
\hline Diarrhea & 2 & 1 & 0 \\
\hline Abdominal pain & 2 & 2 & 0 \\
\hline Skin & & 2 & 0 \\
\hline Rash & 9 & 2 & 0 \\
\hline Alopecia & 11 & & 1 \\
\hline Hyperpigmentation & 0 & 3 & 1 \\
\hline Psychosomatic & & 1 & 0 \\
\hline Mood changes & 6 & 0 & 0 \\
\hline Irritability & 6 & & 0 \\
\hline Headache & 6 & 3 & 1 \\
\hline Musculoskeletal & & 0 & 0 \\
\hline Muscle ache & 4 & & 1 \\
\hline Bone pain & 5 & 0 & 1 \\
\hline Others & & 1 & \\
\hline Elevated liver enzymes & 0 & 2 & \\
\hline Leucopenia & 2 & 3 & \\
\hline Cushingoid habitus & 12 & & \\
\hline Hospitalizations (SAE) & 18 & & \\
\hline
\end{tabular}

Nausea was the most common side effect with levamisole therapy but tolerance developed with nausea after 4 to 8 weeks. Eight children treated with levamisole therapy had transient rise of BP during severe bacteraemia and peritonitis leading to acute kidney injury. The raised BP was normalized with median 3 months duration in all the subjects.

Total twenty-two serious adverse events (SAE) were documented, 18 with levamisole, 3 with Cyp and 1 with MMF treated subjects, which required hospitalizations, which could be attributed to the complication of NS itself. But all the adverse events and SAEs were reported to the local ADR monitoring centre under the pharmacovigilance programme of India (PvPI).
Causality assessment using WHO UMC causality assessment scale revealed that only $0.72 \%$ ADRs were under probable category, while rest were possible. Severity of ADRs was assessed using Hartwig-Seigel severity assessment scale. $0.72 \%$ ADR $(n=1)$ was assessed to be 'moderate' under level 4, while rest were 'mild' under level 1.

\section{DISCUSSION}

Nephrotic syndrome is a common clinical condition in Asian children. One of the most difficult tasks in pediatric nephrology is the care of idiopathic nephrotic syndrome patients with multiple relapses like FRNS, and the situation is even more difficult in SDNS and SRNS 
patients. These patients are candidates for treatment with steroid-sparing agents. ${ }^{9-11}$ The present study included 104 subjects, of which 44 were diagnosed as SDNS, while 56 were diagnosed as FRNS, and 4 patients were diagnosed as SRNS. The mean age at onset of NS was 4.8 years in this study, which is in contrast to 3.4 years as noted in other studies conducted in Asians and 4.2 years in Europeans. In young children, boys are more commonly affected than girls (ratio 3:2) but in teenagers and adults, the sex ratio is approximately equal. ${ }^{12}$ This study noted the ratio as $2.6: 1$.

The immunomodulatory agents like levamisole, cyclophosphamide, MMF, chlorambucil and immunosuppressant like calcineurin inhibitors (cyclosporine, tacrolimus) are usually used as SPA. In this study authors have observed levamisole, cyclophosphamide and MMF were commonly used SPAs. Out of a total of 104 patients enrolled in the study, levamisole, Cyp and MMF were commonly used SPAs. Among them levamisole was the most commonly used SPA. There are certain studies in favor of levamisole usage as SPA in such subjects. Wardena A et al, reported a retrospective comparative study in which levamisole was prescribed as a first steroid-sparing agent for 65 children; disease control was achieved in 30\%. They concluded that levamisole is an attractive steroid-sparing agent. ${ }^{13}$ All of the SDNS subjects were put on levamisole; while 53 among total 56 FRNS subjects were started with levamisole and 3 with Cyp. In case of 4 SRNS, 2 were started with Cyp and 2 with MMF.

One should also keep in mind that treatment choices in this condition are not always driven by drug efficacy alone. Drug tolerability and safety profiles are important considerations, especially when they are given for a prolonged-periods at a time. For example, cyclophosphamide is associated with significant gonadotoxicity and increased long-term cancer risk, while CNIs are potentially nephrotoxic, neurotoxic, and diabetogenic. ${ }^{14}$ CNIs also produce disturbing cosmetic side effects and require regular, close drug monitoring. ${ }^{14,15}$ The side effect profiles of levamisole and MMF are much more patient friendly. ${ }^{14,15}$ Levamisole is generally well tolerated. Its main side effect is neutropenia, which necessitates a close follow-up of the leukocyte count. However, leukocytosis is always reversible after withdrawing the drug. Other rarely reported side effects during levamisole treatment for NS included vasculitis, liver toxicity, and convulsions, but these were also always reversible after withdrawal of treatment. ${ }^{16-18}$

In this study sites, nausea was the most common side effect with levamisole therapy though found self-limiting in nature. Transient rise of BP during severe bacteraemia and peritonitis leading to acute kidney injury were noted in $8.24 \%$ subjects Serious adverse event necessitating hospitalization were documented in $22.11 \%$ subjects, however the cause can also be attributed to the disease progression, thus definite causality for the same cannot be established. Once they were in remission after 2 to 3 weeks, they were restarted on therapy without any further complications. However, the study has its limitation of small sample size. Long-term use of levamisole in maintaining remission needs to be assessed in larger prospective randomized trials. Authors were not able to comment on SRNS treatment because of limited number of patients on SRNS.

\section{CONCLUSION}

This study found that levamisole is most commonly used SPA in treating FRNS and SDNS in children, in the two tertiary hospital set-ups under study. Levamisole being a very efficacious, safe and easily affordable drug, should be used as an initial first line SPA in treating FRNS and SDNS children. Levamisole and MMF are much more patient friendly, sharing a mild adverse reaction profile.

Funding: No funding sources

Conflict of interest: None declared

Ethical approval: The study was approved by the Institutional Ethics Committee

\section{REFERENCES}

1. Nephrotic syndrome in children: prediction of histopathology from clinical and laboratory characteristics at time of diagnosis. A report of the International Study of Kidney Disease Children. Kidney Int. 1978;13:159-65.

2. The primary nephrotic syndrome in children. Identification of patients with minimal change nephrotic syndrome from initial response to prednisone. A report of the International study of kidney disease in children. $\mathrm{J}$ Pediatr. 1981;98(4):561-4.

3. Niaudet P. Steroid-sensitive idiopathic nephrotic syndrome. In: Avner ED, Harmon WE, Niaudet P, editors. Pediatric nephrology. $5^{\text {th }}$ ed. Philadelphia: Lippincott Williams and Wilkins; 2004:545-573.

4. Schulman SL, Kaiser BA, Polinsky MS, Srinivasan $\mathrm{R}$, Baluarte HJ. Predicting the response to cytotoxic therapy for childhood nephrotic syndrome: superiority of response to corticosteroid therapy over histopathologic patterns. J Pediatr. 1988;113:996-1001.

5. Steroid-sensitive nephrotic syndrome in children. In: Avner ED, Harmon WE, Niaudet P, editors. Pediatric Nephrology. Philadelphia: Lippincott Williams and Wilkins; 2004:543-556.

6. Hodson EM, Craig JC, Willis NS. Evidence-based management of steroid-sensitive nephrotic syndrome. Pediatr Nephrol. 2005;20:1523-30.

7. The use of the WHO-UMC system for standardised case causality assessment. Available at: http://whoumc.org/Graphics/24734.pdf. Accessed on $15^{\text {th }}$ January 2020. 
8. Hartwig SC, Siegel J, Schneider PJ. Preventability and severity assessment in reporting adverse drug reactions. Am J Hosp Pharm. 1992;49(9):2229-32.

9. Neuhaus TJ, Fay J, Dillon MJ, Trompeter RS, Barratt TM. Alternative treatment to corticosteroids in steroid sensitive idiopathic nephrotic syndrome. Arch Dis Child. 1994;71:522-6.

10. Consensus statement on management and audit potential for steroid responsive nephrotic syndrome. Report of a workshop by the British Association for Paediatric Nephrology and Research Unit. Royal College of Physicians. Arch Dis Child. 1994;70:151-7.

11. Trompeter RS. Minimal change nephrotic syndrome and cyclophosphamide. Arch Dis Child. 1986;61:727-9.

12. Andreoli SP. Racial and ethnic differences in the incidence and progression of focal segmental glomerulosclerosis in children. Adv Renal Replace Ther. 2004;11:105-9.

13. Bagga A, Sharma A, Srivastata RN. Levamisole therapy in corticosteroid dependent nephrotic syndrome. Pediatr Nephrol. 1997;11:415-7.

14. Lombel RM, Gipson DS, Hodson EM. Kidney disease: improving global outcomes. Treatment of steroid-sensitive nephrotic syndrome: new guidelines from KDIGO. Pediatr Nephrol. 2013;28:415-61.

15. Pravitsitthikul N, Willis NS, Hodson EM. Noncorticosteroid immunosuppressive medications for steroid-sensitive nephrotic syndrome in children. Cochrane Database Syst Rev. 2013;10:CD002290.

16. Barbano G, Ginevri F, Ghiggeri GM, Gusmano R. Disseminated autoimmune disease during levamisole treatment of nephrotic syndrome. Pediatr Nephrol. 1999;13:602-3.

17. Bulugahapitiya DT. Liver toxicity in a nephrotic patient treated with levamisole. Arch Dis Child. 1997;76:289.

18. Palcoux JB, Niaudet P, Goumy P. Side effects of levamisole in children with nephrosis. Pediatr Nephrol. 1994;8:263-4.

Cite this article as: Begum SA, Tripathi SK, Nandy M, Ghosh SK, Mukherjee S, Saha D. Relative safety of steroid sparing agents in frequently relapsing, steroid dependent and steroid resistant nephrotic syndrome in pediatric patients. Int J Contemp Pediatr 2020;7:1762-6. 